\title{
Atividade antimicrobiana e sinérgica das frações das folhas de Schinopsis brasiliensis Engl. frente a clones multirresistentes de Staphylococcus aureus
}

SARAIVA, A.M. ${ }^{1 *}$; SARAIVA, C.L. ${ }^{1}$; CORDEIRO, R.P. ${ }^{2}$; SOARES, R.R. ${ }^{1}$; XAVIER, H.S.. ${ }^{1}$ CAETANO, N. ${ }^{1}$ ${ }^{1}$ Universidade Federal de Pernambuco, CEP: 50.740-521, Recife-PE, Brasil; ${ }^{2}$ Associação Caruaruense de Ensino Superior, CEP: 55.016-400, Caruaru-PE, Brasil. *e-mail: saraivas2@yahoo.com.br

\begin{abstract}
RESUMO: No presente estudo objetivou-se avaliar a atividade antimicrobiana e sinérgica de 4 frações das folhas de Schinopsis brasiliensis Engl (F1', F2', F1" e F2") frente às cepas Staphylococcus aureus MRSA multirresistentes. Os métodos utilizados foram poços de difusão em ágar, concentração mínima inibitória (CMI) - diluição em ágar, e bioautografia. Nos resultados bioautográficos observou-se três halos de inibição relacionados, no mínimo, à quatro constituintes ativos; sendo dois deles isolados das folhas (galato de metila e ácido

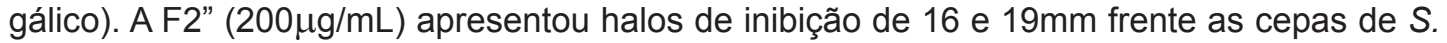
aureus multirresistente e Klebsiella pneumoniae, e CMI $100 \mu \mathrm{g} / \mathrm{mL}$, respectivamente. Quanto as

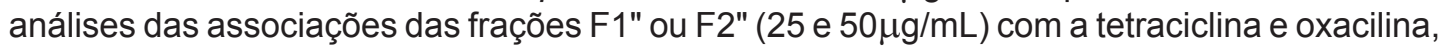
mostraram ações aditiva e sinérgica para a F2" $(50 \mu \mathrm{g} / \mathrm{mL})$, embora não suficiente para que a CMI atingisse valores inferiores a 2 e $4 \mu \mathrm{g} / \mathrm{mL}$, necessário para serem classificadas como cepas sensíveis a oxacilina e tetraciclina, respectivamente. "Assim, conclui-se que a F2" das folhas de $S$. brasiliensis apresentou potencial antimicrobiano frente às cepas de $S$. aureus MRSA multirresistentes e que as associações das frações com os antibióticos testados não apresentaram benefícios não justificando o uso concomitante.
\end{abstract}

Palavras-chave: Schinopsis brasiliensis, Staphylococcus aureus, Atividade antimicrobiana, Multidroga-Resistente.

\begin{abstract}
Antimicrobial and synergic activity of fractions from the leaves of Schinopsis brasiliensis Engl. against Staphylococcus aureus multiresistant clones. The aim of this study was to evaluate the antimicrobial and synergic activity of 4 leaf fractions of Schinopsis brasiliensis Engl (F1', F2', F1" and F2") against multidrug-resistant Staphylococcus aureus strains. The used methods were agar well diffusion, minimum inhibitory concentration (MIC) agar dilution, and bioautography. The bioautographic results showed three inhibition zones that corresponded to at least four active compounds, two of which (methyl gallate and gallic acid) have already been isolated from leaves. The F2" $(200 \mu \mathrm{g} / \mathrm{mL})$ fraction showed inhibition zones of $16 \mathrm{~mm}$ and $19 \mathrm{~mm}$ against $S$. aureus multidrug-resistant and Klebsiella pneumoniae strains and a MIC value of $100 \mu \mathrm{g} / \mathrm{mL}$, respectively. The analyses of associations of fraction F1" or F2" $(25$ and $50 \mu \mathrm{g} / \mathrm{mL}$ ) with tetracycline and oxacillin showed additive and synergistic action for F2" $(50 \mu \mathrm{g} / \mathrm{mL})$, although it was not enough to decrease the MIC values to less than 2 and $4 \mu \mathrm{g} /$ $\mathrm{mL}$, necessary to classify the strains as susceptible to oxacillin and tetracycline, respectively. Thus, it was concluded that F2" from the leaves of $S$. brasiliensis showed antimicrobial potential against multidrug-resistant MRSA strains, and the associations of the fractions with the tested antibiotics showed no benefits, not justifying their concomitant use.
\end{abstract}

Key words: Schinopsis brasiliensis, Staphylococcus aureus, Antimicrobial activity, Multidrugresistant strains.

\section{INTRODUÇÃO}

As doenças infecciosas são as principais causas de mortes prematuras no mundo, sendo estimado 15 milhões de óbitos por ano. O crescimento da resistência bacteriana é um fator importante na ocorrência deste quantitativo de mortes, além de que, esta ameaça também dificulta a cura e eleva os

Recebido para publicação em 27/07/2011

Aceito para publicação em 26/04/2012

Rev. Bras. PI. Med., Campinas, v.15, n.2, p.199-207, 2013. 
gastos com a assistência a saúde (WHO, 2008). Na procura de novas alternativas para tratar as infecções por bactérias multidrogas resistentes (MDR), interessa a descoberta de novos produtos de origem vegetal ou de síntese. O gênero Schinopsis pertence à família Anacardiaceae, classe Dicotiledoneae, subclasse das Rosidae e ordem Sapindales (Prado et al. 1995), que crescem na América do Sul, particularmente Schinopsis lorentizii e Schinopsis balansae, no norte da Argentina e no Paraguai, e Schinopsis brasiliensis árvore endêmica brasileira encontrada na caatinga e pantanal Mato-grossense, popularmente conhecida por "braúna", "baraúna", "braúna-do-sertão", "braúna-parda", "quebracho", "chamacoco" e "chamucoco" (Carvalho, 2011; Cardoso et al. 2005; Prado et al. 1995). Na medicina popular as folhas, casca, caule, entrecasca, resina e frutos de $S$. brasiliensis são usados como antiinflamatório em geral, na gripe, febre, tosse, diarréia, disenteria, fraturas (Albuquerque, 2006; Almeida et al. 2005; Albuquerque et al. 2007) e antimicrobiano (Saraiva, 2007).

O estudo das associações de extratos e frações de plantas de uso medicinal com os medicamentos utilizados se faz necessário, em particular, as interações com os antimicrobianos utilizados na clínica, que podem causar interferência na ação farmacológica do antibacteriano, ocasionando recidiva da doença infecciosa, acompanhado de seleção de microrganismos resistentes.

Por tudo isso, justifica-se, inicialmente, o estudo in vitro para determinar-se o grau de sinergismo/antagonismo dos extratos e frações com alguns antibióticos utilizados na terapêutica clínica, frente a microorganismos que tenham seu perfil de sensibilidade e resistência determinados (Wang et al. 2003; Stermitz et al. 2000).

\section{MATERIAL E MÉTODOS}

\section{Coleta da planta}

A planta, Schinopsis brasiliensis Engl., foi coletada na cidade de Carnaubeira da Penha, Sertão de Pernambuco, nas coordenadas geográficas de 08 $19^{\prime} 09^{\prime \prime}$ de latitude sul, $38^{\circ} 44^{\prime} 41^{\prime \prime}$ de longitude oeste e altitude aproximada de 446 metros (MME, 2005), entre os meses de março e julho de 2004. A exsicata da planta foi identificada pela responsável técnica do Instituto Agronômico de Pernambuco e depositada no Herbário, recebendo o número de registro 70.007 .

\section{Preparação do Extrato}

As folhas de Schinopsis brasiliensis foram secas, trituradas, pesadas e feitas três extrações sucessivas, pelo processo de decocção utilizando três solventes de polaridades diferentes (n-hexano, acetato de etila e metanol) e deixados em repouso pelo período de 72 horas para cada solvente. O extrato assim obtido foi evaporado (Marconi MA120) sob pressão reduzida $\left(45^{\circ} \mathrm{C}\right)$, sendo então pesados e calculados seus rendimentos (Saraiva, 2007).

\section{Fracionamento do Extrato}

A partir de $5 \mathrm{~g}$ do extrato metanólico das folhas (BFM) foi realizado fracionamento em coluna de sílica-gel, tendo como fase móvel o solvente acetato de etila, onde se obteve onze frações (100 $\mathrm{mL}$ ), juntando-se as duas primeiras (F1' - $3120 \mathrm{mg}$ ) e a terceira com a quarta (F2' - $627 \mathrm{mg})$. A partir de F1' realizou-se uma nova coluna cromatográfica, tendo como fase estacionária a Sephadex LH-20 e o metanol como fase móvel, obtendo-se 103 frações $(10 \mathrm{~mL})$, das quais juntaram-se as frações da $14^{\mathrm{a}}$ à $28^{\mathrm{a}}$ (F1" - $\left.1290 \mathrm{mg}\right)$ e da $50^{\mathrm{a}}$ à $70^{\mathrm{a}}$ (F2'”' $\left.-386 \mathrm{mg}\right)$, após visualização em cromatografia em camada delgada.

\section{Atividade Antimicrobiana}

\section{Linhagens Microbianas}

Nos estudos foram utilizadas vinte cepas de Staphylococcus aureus, das quais dezenove isolados clínicos e uma cepa padrão. Dos dezenove isolados de $S$. aureus, dezesseis são cepas multirresistentes (nove clones epidêmico brasileiro - A cinco clones pediátricos - $B$ e dois clones esporádicos - $G$, I) e três cepas de $S$. aureus sensíveis a meticilina (MSSA) (Tabela 1) (Miranda et al. 2007).

Também foram estudadas outras bactérias Gram negativas e Gram positiva, todas cepas padrão ATCC (Tabela 2).

A fim de avaliar a atividade antifúngica das frações das folhas de Schinopsis brasiliensis foi realizado testes frente a três isolados clínicos leveduriformes (Tabela 3).

\section{Preparo dos Inóculos microbianos}

Os inóculos bacterianos e fúngicas, $10^{8} \mathrm{e}$ $10^{6} \mathrm{UFC} / \mathrm{mL}$ respectivamente, foram padronizados conforme as normas da Clinical Laboratory Standards Institute (CLSI, 2003; 2004).

Halos de inibição - Poços difusão em ágar

Os produtos testes foram preparados: tetraciclina (Tet) $300 \mu \mathrm{g} / \mathrm{mL}$ (bactérias), cetoconazol (Cet) $500 \mu \mathrm{g} / \mathrm{mL}$ (Leveduras) e as frações (F1', F2', F1" e F2") $2000 \mu \mathrm{g} / \mathrm{mL}$.

Os inóculos (Bactérias ou leveduras) foram semeados (swab estéril) na superfície das placas de ágar Mueller Hinton (MH) (CLSI, 2003) ou ágar 
TABELA 1. Linhagens de Staphylococcus aureus

\begin{tabular}{llll}
\hline Cepas & Perfil & Clone & Origem \\
\hline AM594 & MRSA & $\mathrm{A}_{13}$ & Ponta de cateter \\
AM599 & MRSA & $\mathrm{B}_{3}$ & Secreção de úlcera \\
AM642 & MRSA & $\mathrm{B}_{5}$ & Secreção \\
AM771 & MRSA & $\mathrm{B}_{3}$ & Secreção de cateter \\
AM791 & MRSA & $\mathrm{A}_{9}$ & Secreção de saída tenckoff \\
AM793 & MRSA & $\mathrm{A}_{1}$ & Secreção traqueal \\
AM799 & MRSA & $\mathrm{A}_{1}$ & Ponta de sonda vesical \\
AM837 & MRSA & $\mathrm{A}_{8}$ & Ponta de cateter \\
AM858 & MRSA & $\mathrm{A}_{7}$ & Ponta de cateter \\
AM860 & MRSA & $\mathrm{B}_{2}$ & Hemocultura \\
AM872 & MRSA & $\mathrm{G}$ & Urina \\
AM876 & MRSA & $\mathrm{I}$ & Hemocultura \\
AM895 & MRSA & $\mathrm{A}_{5}$ & Hemocultura \\
AM902 & MRSA & $\mathrm{A}_{3}$ & Secreção de orifício \\
AM922 & MRSA & $\mathrm{B}_{4}$ & Ferida perna esq. \\
AM948 & MRSA & $\mathrm{A}_{10}$ & Ponta de cateter \\
AM532 & MSSA & - & Secreção Ferida operatória \\
AM632 & MSSA & - & Ferida operatória \\
AM672 & MSSA & - & Secreção de cateter \\
AM103 & - & - & ATCC 6538 \\
\hline AM: & & & \\
\hline
\end{tabular}

AM: Coleção do Laboratório de Análises Microbiológicas Depto. de Ciências Farmacêuticas - UFPE; ATCC: American Type Culture Collection; Clone A: Clone Epidêmico Brasileiro (CEB); Clone I, G: Clone Esporádico; Clone B: Clone Pediátrico; MRSA: Staphylococcus aureus Meticilina Resistente; MSSA: Staphylococcus aureus Meticilina Sensível.

TABELA 2. Linhagens bacterianas de interesse clínico.

\begin{tabular}{lll}
\hline \multicolumn{2}{c}{ Cepas } & Origem \\
\hline AM31 & Escherichia coli A & TCC 9723 \\
AM50 & Klebsiella pneumoniae & ATCC 10031 \\
AM128 & Enterococcus faecalis & ATCC 33186 \\
AM149 & Salmonella spp & ATCC 8387 \\
AM206 & Pseudomonas aeruginosa & ATCC 14502
\end{tabular}

AM: Coleção do Laboratório de Análises Microbiológicas Depto. de Ciências Farmacêuticas - UFPE; ATCC: American Type Culture Collection

TABELA 3. Linhagens Leveduriformes de interesse clínico.

\begin{tabular}{lll}
\hline & Cepas & Origem \\
\hline AM1158 & Candida albicans & Urina \\
AM1181 & Candida tropicalis & Swab retal \\
AM1168 & Candida krusei & Sangue \\
\hline
\end{tabular}

AM: Coleção do Laboratório de Análises Microbiológicas Depto. de Ciências Farmacêuticas - UFPE.
Sabouraud (CLSI, 2004), respectivamente, feito poços de $6 \mathrm{~mm}$ e aplicados $100 \mu \mathrm{l}$ dos produtos testes nos poços, sendo as placas incubadas a $37^{\circ} \mathrm{C}$ por 24h. A classificação do potencial antimicrobiano, por essa técnica, se deu pelos diâmetros dos halos de inibição observados: < 9mm, inativo; $9-12 \mathrm{~mm}$, pouco ativo; 13 - 18mm, ativo; > 18mm, muito ativo. Halos com diâmetro $<9 \mathrm{~mm}$, inativo; $9-12 \mathrm{~mm}$, pouco ativo; $13-18 \mathrm{~mm}$, ativo; $>18 \mathrm{~mm}$, muito ativo (Alves et al. 2000).

\section{em ágar}

Concentração Mínima Inibitória - Diluição

$\mathrm{Na}$ técnica para determinação da concentração mínima inibitória (CMI)/diluição em ágar das frações (F1" e F2") e os antibióticos (Tet e oxacilina - Oxa) foram incorporados ao ágar Mueller Hinton (MH), obtendo as respectivas concentrações finais de $1,56 \mu \mathrm{g} / \mathrm{mL}$ à $100 \mu \mathrm{g} / \mathrm{mL}$ (1:10) e $0,25 \mu \mathrm{g} / \mathrm{mL}$ à $64 \mu \mathrm{g} / \mathrm{mL}$ (1:10). Os inóculos bacterianos $\left(10^{8} \mathrm{UFC} \mu \mathrm{g} / \mathrm{mL}\right)$ foram depositados na superfície utilizando o multiinoculador de Stears, e então incubou-se a $37^{\circ} \mathrm{C}$ por $24 \mathrm{~h}$. Foi realizado controle do DMSO a $30 \%$ e controle positivo. Para a determinação da CMI da Oxa, foi adicionado + $2 \% \mathrm{NaCl}$ ao meio ágar $\mathrm{MH}$ e incubado a $35^{\circ} \mathrm{C}$ por 24h (CLSI, 2003). O potencial antimicrobiano foi determinado pela medida das CMI das frações dos extratos vegetais, sendo consideradas muito ativas, aquelas que apresentam $\mathrm{CMI} \leq 50 \mu \mathrm{g} / \mathrm{mL}$; ativos com CMI entre $>50-100 \mu \mathrm{g} / \mathrm{mL}$; moderadamente ativos com CMI de $>100-200 \mu \mathrm{g} / \mathrm{mL}$; baixa atividade com CMI de >200 - 500 $\mu \mathrm{g} / \mathrm{mL}$; inativos com CMI > $500 \mu \mathrm{g} / \mathrm{mL}$.

Teste sinérgismo-antagonismo Concentração Mínima Inibitória - Diluição em ágar

Seguindo os mesmos procedimentos para determinação da CMI dos antibióticos (Tet e Oxa), fez-se quatro novas séries do ensaio com a adição das frações (F1" ou F2") nas concentrações de $50 \mu \mathrm{g} /$ $\mathrm{mL}$ ou $25 \mu \mathrm{g} / \mathrm{mL}$, aproximadamente $50 \%$ e $25 \%$ da CMI destas, respectivamente. Fórmula de obtenção do índice da concentração inibitória da fração (Fractional Inhibitory Concentration Index - $\mathrm{FICl}$ ). A: Antibiótico; B: fração; $\mathrm{FICl}=\mathrm{CMI}(\mathrm{A}+\mathrm{B}) / \mathrm{CMI}(\mathrm{A})$ + Concentração de (B) na associação/CMI(B); Parâmetros de avaliação: $\mathrm{FICl}>2$ - Antagonismo; $\mathrm{FICl}>1$ e d" 2 - Indiferente; $\mathrm{FICl}>0,5$ e $\leq 1$ - Aditivo; $\mathrm{FICl} \leq 0,5$ - Sinergismo.

\section{Bioautografia}

As placas desenvolvidas em duplicata no sistema (acetato de etila/ácido fórmico/ácido acético/água - 100:3:3:3 v/v), sendo uma utilizada como referência e revelada com 2-Aminoetildifenil 
borinato e a outra para bioautografia, a qual ficou sob corrente de ar por 6h, para retirada do resíduo ácido. As placas cromatográficas foram instaladas, numa placa de Petri e recobertas com $20 \mathrm{~mL}$ meio fundido de ágar $\mathrm{MH}\left(56 \pm 1^{\circ} \mathrm{C}\right)$ inoculada com uma suspensão salina de $S$. aureus ATCC $6538(18 \mathrm{~mL}$ de meio ágar $\mathrm{MH}+2 \mathrm{~mL}$ da suspensão bacteriana a $10^{8} \mathrm{UFC} / \mathrm{mL}$ ). Após solidificação do meio de cultivo, houve um tempo de pré-difusão de 30 minutos à temperatura ambiente e então incubada por 24 horas a $37 \pm 1^{\circ} \mathrm{C}$. Após este período a bioautografia foi revelada com uma solução de 2,3,5-trifeniltetrazólio à $2,5 \mathrm{mg} / \mathrm{mL}$ e novamente incubada por mais 4 horas.

A presença de zona de inibição, indica a existência de composto ativo (Pessini et al. 2003).

\section{RESULTADO E DISCUSSÃO}

Para confirmação do perfil de sensibilidade e resistência das bactérias e fungos ensaiados, utilizamos como antimicrobianos de referencia à tetraciclina e o cetoconazol, respectivamente. Também, foram utilizadas bactérias e leveduras de diferentes gêneros e/ou espécies para realizar-se uma triagem da atividade antimicrobiana das frações do extrato metanólico das folhas de S. brasiliensis.

No estudo bioautográfico observou-se halo de inibição no ponto de aplicação (molécula 4), o que justificaria a atividade antimicrobiana da F2" e dois halos acima, que podem ser resultado de até três moléculas (1, 2 e 3 ), o que justificaria a atividade

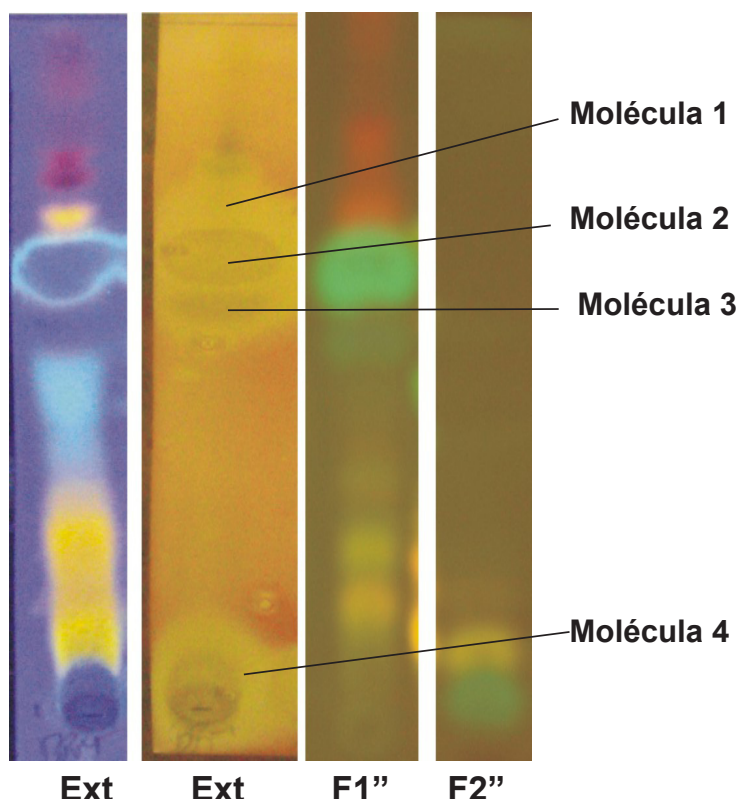

FIGURA 1. Bioautografia do extrato metanólico (Ext) das folhas de Schinopsis brasiliensis

F1" e F2": Frações obtidas da coluna em Sephadex LH-20

antimicrobiana da F1"(Figura 1).

Na técnica poços difusão em ágar (Gráfico 1), observou-se os maiores halos de inibição, sendo da ordem de 20,19,19, 19 e 18mm de diâmetro frente as cepas de Candida albicans, Candida

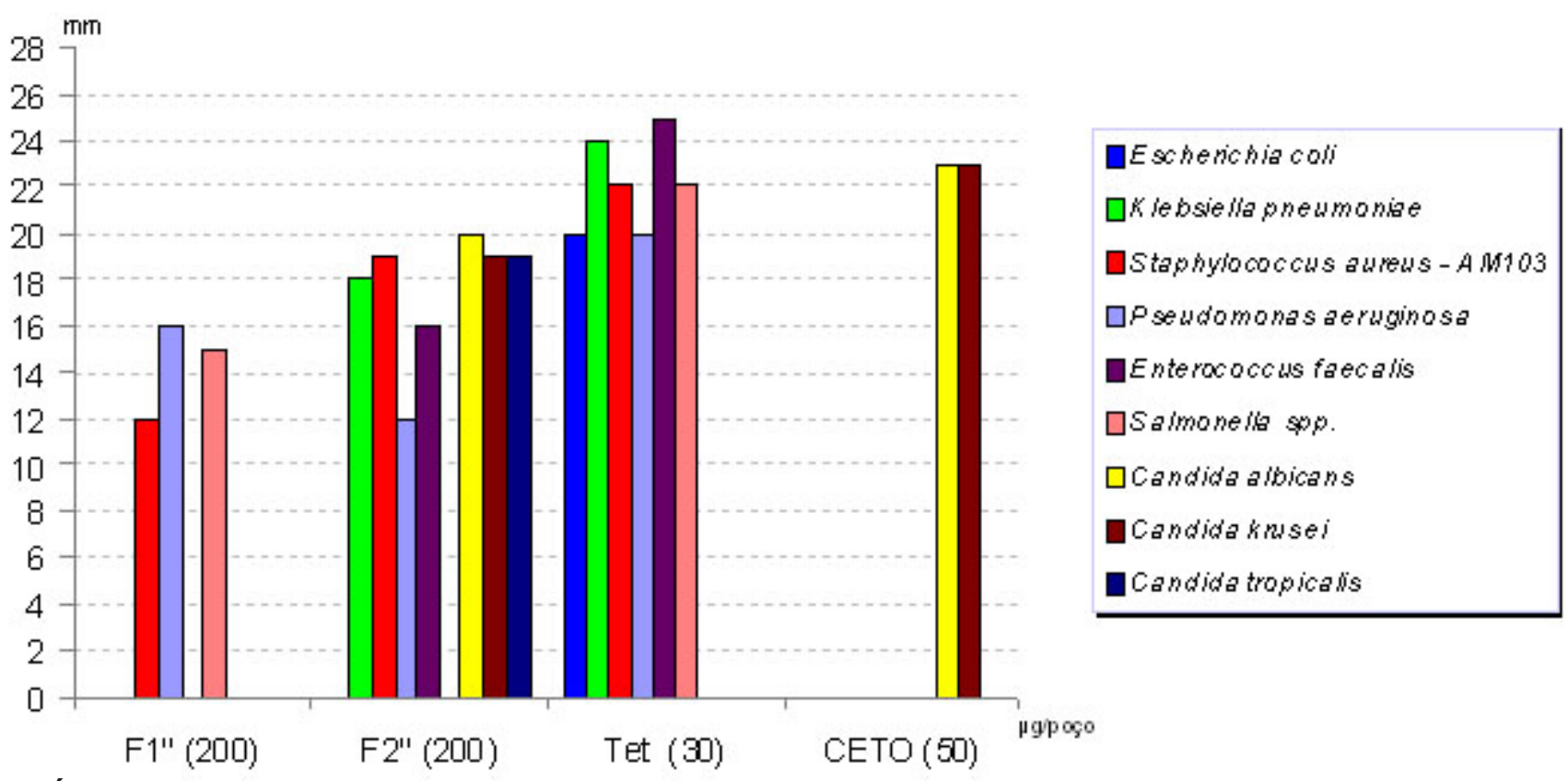

GRÁFICO 1. Atividade antimicrobiana das frações de Schinopsis brasiliensis frente bactérias e leveduras de interesse clínico

F1" e F2": Frações obtidas da coluna em Sephadex LH-20; AM: Coleção do Laboratório de Análises Microbiológicas - Departamento de Ciências Farmacêuticas - UFPE; 
krusei, Candida tropicalis, Staphylococcus aureus e Klebsiella pneumoniae, respectivamente, referente a fração F2" (200 g/poço), classificados como muito ativos, e ativo frente a cepa se $K$. pneumoniae.

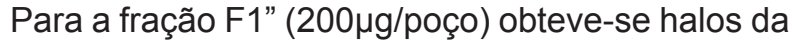
ordem de 15 e $16 \mathrm{~mm}$ frente as cepas de Salmonella serotipo Montevidéu e Pseudomonas aeruginosa, sendo classificados como ativos (Alves, 2000).

As CMI das frações das folhas de $S$. brasiliensis frente às bactérias Gram positivas e Gram negativas apresentaram-se como muito ativo e ativo, em particular, frente às cepas de $E$. coli e $S$. aureus para F1" exibindo CMI de 100 e $50 \mu \mathrm{g} / \mathrm{mL}$ e F2" CMI de 50 e $25 \mu \mathrm{g} / \mathrm{mL}$, respectivamente (Tabela 4). As CMI confirmaram a atividade antimicrobiana das F1" e F2" para a cepa de S. aureus ATCC 6538, que foi evidenciada também pela técnica de poços difusão em ágar.
No estudo antimicrobiano das frações (F1', F2', F1" e F2") das folhas de S. brasiliensis frente às cepas de $S$. aureus MRSA multirresistentes, observou-se que a fração F2" resultou nos maiores halos de inibição, sendo classificados como ativos, pelos parâmetros de Alves et al. (2000) e com media de halos de inibição de $16 \mathrm{~mm}$. Enquanto que as frações F1' e F2' apresentaram média de halos de inibição de 15 e $14 \mathrm{~mm}$, respectivamente, sendo ambas classificadas também como ativas. Para a F1", não observou-se halos de inibição na concentração de $200 \mu \mathrm{g} /$ poço frente as cepas de $S$. aureus multirresistentes (Gráfico 2).

$\mathrm{Na}$ determinação das $\mathrm{CMI}$ das frações ( $\mathrm{F} 1$ ', F2', F1" e F2") das folhas de S. brasiliensis frente às cepas de $S$. aureus MRSA multirresistentes, a F2" apresentou-se com as menores CMI, igual ou menor que $100 \mu \mathrm{g} / \mathrm{mL}$, sendo classificadas como

TABELA 4. Concentração Mínima inibitória (CMI) das frações das folhas de Schinopsis brasiliensis

\begin{tabular}{llrrrrr}
\hline & Cepas & \multicolumn{5}{c}{ CMI $(\mu \mathbf{g} / \mathbf{m L})$} \\
\cline { 3 - 7 } & & F1' & F2' & F1" & F2" & Tet \\
\hline AM31 & E. coli & $>100$ & $>100$ & 100 & 50 & 4,00 \\
AM50 & K. pneumoniae & $>100$ & $>100$ & $>100$ & 100 & 0,50 \\
AM103 & S. aureus & $>100$ & 100 & 50,0 & 25,0 & 0,25 \\
AM128 & E. faecalis & $>100$ & $>100$ & $>100$ & $>100$ & 1,00 \\
AM149 & Salmonella spp. & $>100$ & $>100$ & $>100$ & $>100$ & 1,00
\end{tabular}

F1', F2': frações obtidas da coluna de sílica; F1" e F2": Frações obtidas da coluna em Sephadex LH-20; Tet: Tetraciclina; AM: Coleção do Laboratório de Análises Microbiológicas - Depto. de Ciências Farmacêuticas - UFPE;

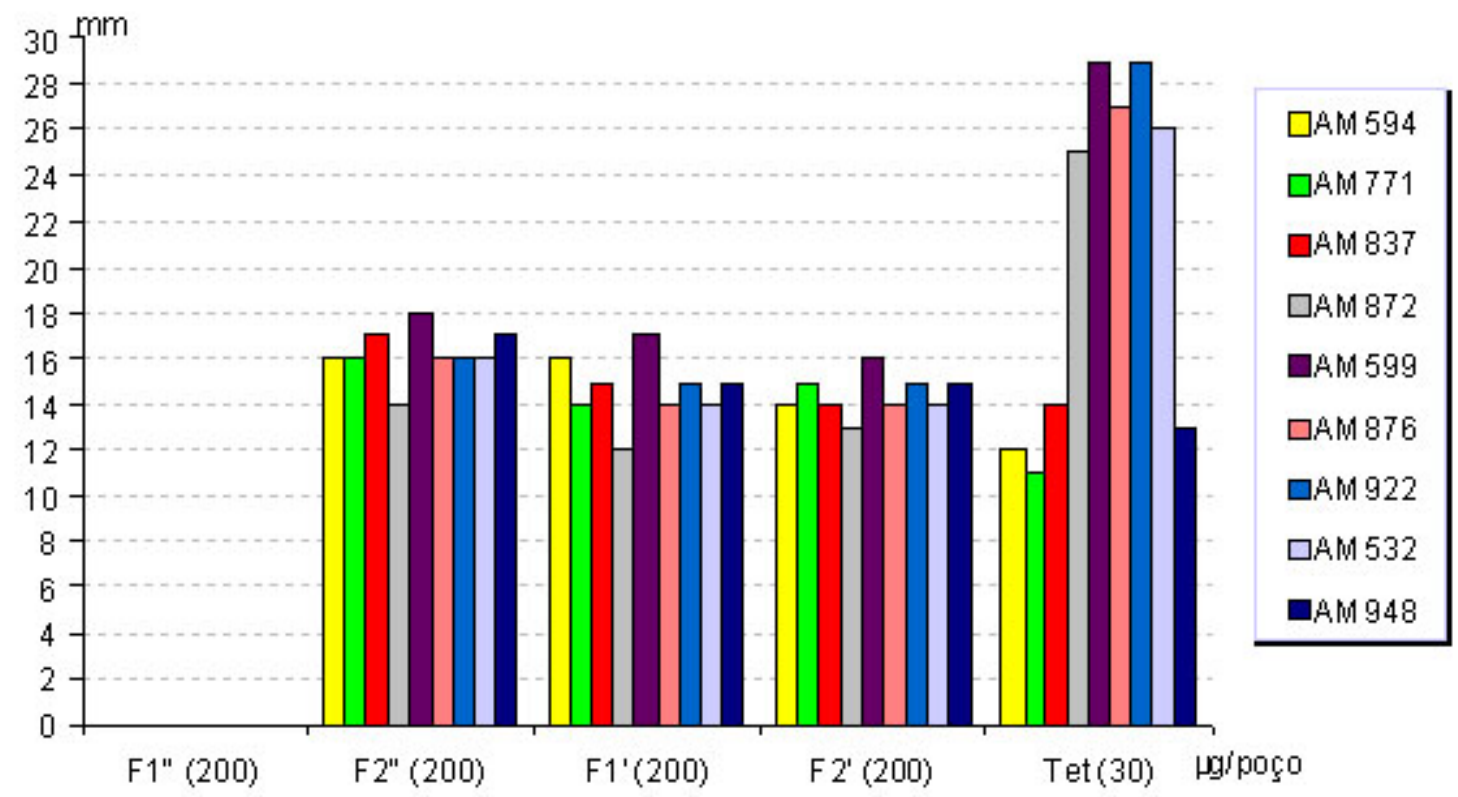

GRÁFICO 2. Atividade antimicrobiana das frações de Schinopsis brasiliensis frente às cepas de Staphylococcus aureus MRSA multirresistentes

F1', F2': frações obtidas da coluna de sílica; F1" e F2": Frações obtidas da coluna em Sephadex LH-20; Tet: Tetraciclina; AM: Coleção do Laboratório de Análises Microbiológicas - Depto. de Ciências Farmacêuticas - UFPE 
TABELA 5. Concentração mínima inibitória das frações das folhas de Schinopsis brasiliensis

\begin{tabular}{|c|c|c|c|c|c|c|c|c|c|}
\hline \multirow{2}{*}{ Código } & \multicolumn{7}{|c|}{ Concentração Mínima Inibitória } & \multicolumn{2}{|c|}{ Perfil de Sensibilidade/Resistência } \\
\hline & & F1' & F2' & F1" & F2" & Oxa & Tet & Sensível & Resistente \\
\hline \multicolumn{10}{|c|}{ S. aureus Meticilina Sensível } \\
\hline AM & 532 & 100 & $>100$ & $>100$ & 50 & $<0,25$ & 0,50 & $1,2,3,4,5,6,7,8$ & - \\
\hline AM & 632 & $>100$ & $>100$ & $>100$ & 100 & 0,50 & 1,00 & $1,3,4,5,6,7$ & 8,2 \\
\hline AM & 672 & $>100$ & $>100$ & $>100$ & 100 & $<0,25$ & 1,00 & $1,2,3,4,5,6$ & 7,8 \\
\hline \multicolumn{10}{|c|}{ S. aureus MRSA - Clone Epidêmico Brasileiro } \\
\hline AM & 594 & 100 & $>100$ & $>100$ & 100 & 256 & 32,0 & 1 & $2,3,4,5,6,7,8$ \\
\hline AM & 771 & $>100$ & $>100$ & 100 & 100 & 32,0 & 0,50 & 1 & $2,3,4,5,6,7,8$ \\
\hline AM & 791 & $>100$ & $>100$ & 100 & 100 & 256 & 16,0 & 1 & $2,3,4,5,6,7,8$ \\
\hline AM & 793 & $>100$ & $>100$ & $>100$ & 100 & 256 & 32,0 & 1 & $2,3,4,5,6,7,8$ \\
\hline AM & 799 & $>100$ & $>100$ & 100 & 100 & 128 & 32,0 & 1 & $2,3,4,5,6,7,8$ \\
\hline AM & 837 & 100 & $>100$ & 50,0 & 25,0 & 64,0 & 32,0 & 1 & $2,3,4,5,6,7,8$ \\
\hline AM & 858 & 100 & $>100$ & 100 & 100 & 128 & 32,0 & 1 & $2,3,4,5,6,7,8$ \\
\hline AM & 860 & 100 & $>100$ & 100 & 50,0 & 64,0 & 32,0 & 1 & $2,3,4,5,6,7,8$ \\
\hline AM & 895 & $>100$ & $>100$ & $>100$ & 100 & 256 & 32,0 & 1 & $2,3,4,5,6,7,8$ \\
\hline AM & 902 & 100 & $>100$ & $>100$ & 100 & 16,0 & 32,0 & 1 & $2,3,4,5,6,7,8$ \\
\hline AM & 948 & 100 & $>100$ & $>100$ & 100 & 258 & 32,0 & 1 & $2,3,4,5,6,7,8$ \\
\hline \multicolumn{10}{|c|}{ S. aureus MRSA - Clone Esporádico } \\
\hline AM & 872 & $>100$ & $>100$ & $>100$ & 100 & 256 & 16,0 & $1,5,2,7,6$ & $3,4,8$ \\
\hline AM & 876 & $>100$ & $>100$ & $>100$ & 100 & 32,0 & 2,00 & $1,5,2,3,6,7$ & 4,8 \\
\hline \multicolumn{10}{|c|}{ S. aureus MRSA - Clone Pediátrico } \\
\hline AM & 642 & $>100$ & $>100$ & $>100$ & 100 & 32,0 & 0,50 & $1,6,7,3$ & $2,5,4,8$ \\
\hline AM & 599 & $>100$ & $>100$ & $>100$ & 100 & 16,0 & $<0,50$ & $1,5,3,6,7$ & $2,4,8$ \\
\hline AM & 922 & $>100$ & $>100$ & $>100$ & 100 & 16,0 & 1,00 & $1,5,2,3,6$ & $4,8,7$ \\
\hline
\end{tabular}

F1', F2': frações obtidas da coluna de sílica; F1" e F2": Frações obtidas da coluna em Sephadex LH-20; 1: Vancomicina; 2: Eritromicina; 3: (Tet) Tetracilina; 4: (Oxa) Oxacilina; 5: Ciprofloxacina; 6: Sulfametoxazol+Trimetoprima; 7: Gentamicina; 8: Penicilina; MRSA: Staphylococcus aureus Meticilina Resistente; AM: Coleção do Laboratório de Análises Microbiológicas - Depto. de Ciências Farmacêuticas - UFPE.

muito ativas e ativas $(\mathrm{CMI} \leq 50$ e $\mathrm{CMI}>50$ e d"100, respectivamente). Para aquelas frações com CMI $>100 \mu \mathrm{g} / \mathrm{mL}$, classificadas como moderadamente ativas, visualizou-se para as F1', F2' e F1" frente as várias cepas de $S$. aureus multirresistentes. Os antimicrobianos de referência confirmaram o perfil de sensibilidade e resistência dos microorganismos testados (Tabela 5).

Devido a atividade antimicrobiana exibida pelas frações (F1" e F2") das folhas de S. brasiliensis foi estudada a interação sinérgica/antagônica, por meio do $\mathrm{FICl}$ (índice da concentração inibitória da fração), contra a oxacilina (família das Penicilinas) e tetraciclina (dá nome a família) antibióticos amplamente utilizados na determinação do perfil de sensibilidade e resistência para as cepas de $S$. aureus.

A F2" $(50 \mu \mathrm{g} / \mathrm{mL})$, aproximadamente à
$50 \%$ da CMI, em associação a tetraciclina (D) apresentou frente a grande maioria das cepas uma ação aditiva. As associações contendo a F1" $(50 \mu \mathrm{g} /$ $\mathrm{mL}(\mathrm{C})$ e $25 \mu \mathrm{g} / \mathrm{mL}(\mathrm{A})$ ) apresentaram uma variação do $\mathrm{FICl}$, sendo na concentração de $25 \mu \mathrm{g} / \mathrm{mL}(\mathrm{A})$, aproximadamente à $25 \%$ da $\mathrm{CMI}$, frente a maioria das cepas, classificadas como indiferente (Tabela 6).

A F2" $(50 \mu \mathrm{g} / \mathrm{mL}$ (d) e $25 \mu \mathrm{g} / \mathrm{mL}$ (b)) em associação a oxacilina apresentou ação aditiva e sinérgica e a F1" $(50 \mu \mathrm{g} / \mathrm{mL}$ (c)) foi observada também uma ação sinérgica frente a quatro e ação aditiva a duas, dentre as sete cepas testadas. Na F1" $(25 \mu \mathrm{g} / \mathrm{mL}(\mathrm{a}))$ houve uma variação do $\mathrm{FICl}$ dentre as cepas testadas (Tabela 7).

As F1" e F2" $(50 \mu \mathrm{g} / \mathrm{mL}$ - c e d) interagiram de maneira positiva (ação aditiva ou sinérgica), na redução da CMI para oxacilina frente às cepas de $S$. aureus MRSA multirresistentes, embora 
TABELA 6. Estudo sinérgico-antagônico das frações de Schinopsis brasiliensis contra tetraciclina frente às cepas de Staphylococcus aureus MRSA multirresistentes

\begin{tabular}{|c|c|c|c|c|c|c|c|c|c|c|c|c|c|c|c|}
\hline \multirow[t]{2}{*}{$\overline{\mathrm{AM}}$} & \multicolumn{7}{|c|}{ CMI } & \multicolumn{4}{|c|}{$\mathrm{FICl}$} & \multicolumn{4}{|c|}{ Resposta } \\
\hline & Tet & F1" & F2" & A & C & B & D & A & C & B & D & A & C & B & D \\
\hline 594 & 16,0 & $>100$ & 100 & 16,0 & 16,0 & 1,00 & 2,00 & 1,13 & 1,25 & 0,31 & 0,63 & IN & IN & SI & SI \\
\hline 599 & 1,00 & $>100$ & 100 & 1,00 & 4,00 & 0,50 & 2,00 & 1,13 & 4,25 & 0,75 & 2,50 & IN & AN & $A D$ & AN \\
\hline 791 & 16,0 & 100 & 100 & 16,0 & 16,0 & 2,00 & 8,00 & 1,25 & 1,50 & 0,38 & 1,00 & IN & IN & $\mathrm{SI}$ & $A D$ \\
\hline 858 & 32,0 & 100 & 100 & 16,0 & 16,0 & 8,00 & 16,0 & 0,75 & 1,00 & 0,50 & 1,00 & $A D$ & $A D$ & SI & $A D$ \\
\hline 872 & 32,0 & $>100$ & 100 & 16,0 & 16,0 & 32,0 & 8,00 & 0,63 & 0,75 & 1,25 & 0,75 & $A D$ & $A D$ & IN & $A D$ \\
\hline 902 & 32,0 & $>100$ & 100 & 32,0 & 64,0 & 32,0 & 16,0 & 1,13 & 2,25 & 1,25 & 1,00 & IN & AN & IN & $A D$ \\
\hline 922 & 1,00 & $>100$ & 100 & 1,00 & 1,00 & 0,25 & 0,25 & 1,13 & 1,25 & 0,50 & 0,75 & IN & IN & SI & $A D$ \\
\hline
\end{tabular}

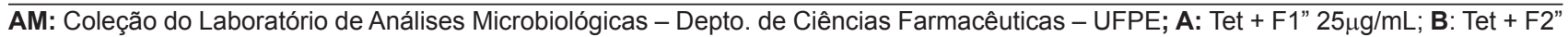
$25 \mu \mathrm{g} / \mathrm{mL}$; C: Tet + F1" $50 \mu \mathrm{g} / \mathrm{mL}$; D: Tet + F2" $50 \mu \mathrm{g} / \mathrm{mL}$; CMI: Concentração Mínima Inibitória; Tet: Tetraciclina; FICl: Índice da Concentração Inibitória da Fração; AN: Antagonismo; IN: Indiferente; AD: Aditivo; SI: Sinergismo.

TABELA 7. Estudo sinérgico-antagônico das frações de Schinopsis brasiliensis contra oxacilina frente às cepas de Staphylococcus aureus MRSA multirresistentes

\begin{tabular}{|c|c|c|c|c|c|c|c|c|c|c|c|c|c|c|c|}
\hline \multirow[t]{2}{*}{$\overline{\mathrm{AM}}$} & \multicolumn{7}{|c|}{ CMI } & \multicolumn{4}{|c|}{$\mathrm{FICl}$} & \multicolumn{4}{|c|}{ Resposta } \\
\hline & Oxa & F1" & F2" & $a$ & c & b & d & $a$ & C & b & d & a & c & b & d \\
\hline$\overline{594}$ & 256 & $>100$ & 100 & 64,0 & 64,0 & 64,0 & 16,0 & 0,38 & 0,50 & 0,50 & 0,56 & SI & SI & SI & $A D$ \\
\hline 599 & 16,0 & $>100$ & 100 & 32,0 & 2,00 & 64,0 & 4,00 & 2,13 & 0,38 & 4,25 & 0,75 & AN & SI & AN & $A D$ \\
\hline 791 & 64,0 & 100 & 100 & 256 & 32,0 & 128 & 8,00 & 4,25 & 1,00 & 2,25 & 0,63 & AN & $A D$ & AN & $A D$ \\
\hline 858 & 256 & 100 & 100 & 64,0 & 64,0 & 256 & 16,0 & 0,50 & 0,75 & 1,25 & 0,56 & SI & $A D$ & IN & $A D$ \\
\hline 872 & 256 & $>100$ & 100 & $>256$ & 256 & 128 & 64,0 & 2,13 & 1,25 & 0,75 & 0,75 & AN & IN & $A D$ & $A D$ \\
\hline 902 & 64,0 & $>100$ & 100 & 128 & 8,00 & 16,0 & 8,00 & 2,13 & 0,38 & 0,5 & 0,63 & AN & SI & SI & $A D$ \\
\hline 922 & 32,0 & $>100$ & 100 & 1,00 & 0,25 & 4,00 & 0,13 & 0,16 & 0,26 & 0,38 & 0,504 & SI & SI & SI & $A D$ \\
\hline
\end{tabular}

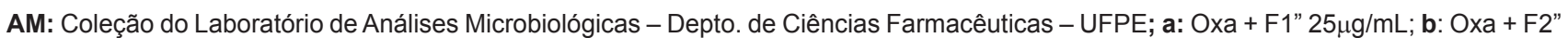

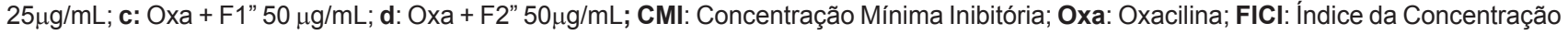
Inibitória da Fração; AN: Antagonismo; IN: Indiferente; AD: Aditivo; SI: Sinergismo.

na maioria dos casos estas reduções não foram o suficiente para que obtivessem valores das $\mathrm{CMI} \leq 2 \mu \mathrm{g} / \mathrm{mL}$, o qual classificaria as cepas de S. aureus como meticilina (Oxacilina) sensível (MSSA ou OSSA), sendo que aqueles com CMI $\geq 4 \mu \mathrm{g} / \mathrm{mL}$ são classificados como resistentes ou seja, Staphylococcus aureus meticilina (oxacilina) resistente (MRSA ou ORSA) (CLSI, 2005).

Em relação às associações das frações das folhas de $S$. brasiliensis com o antibiótico tetraciclina, mostraram-se por meio dos $\mathrm{FICl}$ como indiferentes, frente à maioria das cepas testadas, na concentração de $25 \mu \mathrm{g} / \mathrm{mL}$ (A e B), visto que não houve alteração nos valores das $\mathrm{CMI}$. Na concentração de $50 \mu \mathrm{g} / \mathrm{mL}$ das frações (C e D), em particular frente a F1", foi observada importante ação aditiva e sinérgica, embora as CMI frente às cepas de $S$. aureus multirresistentes não foram a valores classificados como sensíveis ( $\mathrm{CMI} \leq 4$ $\mu \mathrm{g} / \mathrm{mL}$ ) (CLSI, 2005), exceto na associação da tetraciclina com a F2" (25 e $50 \mu \mathrm{g} / \mathrm{mL}-\mathrm{B}$ e D) frente a AM594, uma cepa de Staphylococcus aureus MRSA multirresistente (Clone Epidêmico Brasileiro), só sensível a vancomicina, obtendo as $\mathrm{CMI}$ de $1 \mathrm{e}$ $2 \mu \mathrm{g} / \mathrm{mL}$, respectivamente.

As frações (F1" e F2") em ambas as concentrações (25 e $50 \mu \mathrm{g} / \mathrm{mL}$ ) em associação com os antibióticos (tetraciclina e oxacilina) apresentaram frente a cada cepas multirresistente de $S$. aureus uma variação quanto aos resultados, sendo que algumas frações apresentaram ações sinérgicas e aditivas, correspondentes a uma redução dos valores das $\mathrm{CMI}$ frente às cepas de $S$. aureus multirresistentes, embora também mostraram-se as vezes indiferentes ou mesmo com ação antagônica, não modificando ou elevando as $\mathrm{CMI}$, respectivamente. Estas variações observadas podem ser devidas às características de resistência intrínseca de cada cepa (Souza et al. 2005), visto que os antibióticos foram utilizados como 
agentes principais e as frações (F1" e F2") com agentes secundários, tendo suas concentrações aproximadamente a 25 e $50 \%$ da CMI.

O FICl das frações (F2" e F1") + antibióticos (Tetraciclina e Oxacilina), não demonstraram benefícios quanto a redução da CMI frente as cepas de $S$. aureus MRSA testadas, visto que, quando houve redução das $\mathrm{CMI}$, esta não foram a um valor menor que o estipulado pela CLSI (2005) para que a bactéria fosse classificada como sensível ao antibiótico. Sendo assim, o uso concomitante das frações das folhas de $S$. brasiliensis associados aos antibióticos, tetraciclina e oxacilina in vitro, embora obtendo em alguns casos aumento da ação antimicrobiana dos antibióticos por reduzir as CMI destes, fato importante, no geral não trouxeram benefícios, já que também reduziu o efeito dos antibióticos, frente a algumas cepas multirresistentes de $S$. aureus (ação antagônica).

Nos três halos de inibição observados na bioautografia, e em referência a correspondente cromatografia em camada delgada (CCD) revelada (2-Aminoetildifenil borinato), observou-se que, no mínimo, quatro moléculas ativas foram relacionadas à atividade antimicrobiana do extrato metanólico das folhas (Saraiva et al. 2011), sendo o galato de metila (2) e ácido gálico (3), moléculas já isoladas das folhas de S. brasiliensis (Souza, 1990; Moreira, 2009) e de reconhecida atividade antimicrobiana (Nijeveldt et al. 2001; Zaidi-Yahiaoui et al. 2008). A F2" apresentou melhor atividade antimicrobiana que a F1", embora esta ultima haveria de comportar, no mínimo, duas das quatro moléculas ativas (galato de metila e ácido gálico), visualizados no estudo fitoquímico e na bioautografia, enquanto que a F2" observou-se apenas a molécula 4.

Quanto aos resultados da atividade antimicrobiana das frações das folhas de Schinopsis brasiliensis foram promissores e fornece dados suficientes para continuar as pesquisas, objetivando o isolamento e elucidação estrutural dos compostos com potencial antimicrobiano guiado por bioautografia.

\section{AGRADECIMENTOS}

UFPE; - Grupo Internacional de Pesquisa de Doenças Infecciosas e Resistência Antimicrobiana - GIPDIRA - UFPE

\section{REFERÊNCIAS}

ALBUQUERQUE, U.P. Re-examining hypotheses concerning the use and knowledge of medicinal plants: a study in the Caatinga vegetation of NE Brazil, Journal of Ethnobiology and Ethnomedicine, v.2, n. 30, p.110, 2006.

ALBUQUERQUE, U.P. et al. Medicinal plants of the caatinga (semi-arid) vegetation of NE Brazil: A quantitative approach. Journal of Ethnopharmacology, v.114, n.3, p.325-54, 2007.

ALMEIDA, C.F.C.B.R. et al. Life strategy and chemical composition as predictors of the selection of medicinal plants from the Caatinga (Northeast Brazil). Journal of Arid Environments. v.62, n. 1, p.127-42, 2005.

ALVES, T.M.A. et al. Biological Screening of Brazilian Medicinal Plants. Memórias do Instituto Oswaldo Cruz, v.95, n.3, p.367-73, 2000.

Cardoso, M.P.; David, J.M.; David, J.P. A new alkyl phenol from Schinopsis brasiliensis. Natural Products Research, v.19, n.5, p.431-433, 2005.

Carvalho, P.E.R. Braúna-do-sertão - Schinopsis brasiliensis. Embrapa - Comunicado Técnico 222. p.1-9, 2009. Disponível em: <http://www.cnpf.embrapa. br/> acesso em: 15 out. 2011.

CLSI-Clinical Laboratory Standards Institute. Metodologia dos Testes de Sensibilidade a Agentes Antimicrobianos por Diluição para Bactéria de Crescimento Aeróbico, NCCLS. 2003. 49p.

CLSI-Clinical Laboratory Standards Institute. Normas de Desempenho para Testes de Sensibilidade Antimicrobiana: $15^{\circ}$ Suplemento Informativo. NCCLS. 2005. 176p.

CLSI-Clinical Laboratory Standards Institute. Method for antifungal disk diffusion testing of yeast. NCCLS. 2004. 23p.

Ministério de Minas e Energia (MME). Projeto cadastro de fontes de abastecimento por água subterrânea diagnóstico do Município de Carnaubeira da Penha, 2005, 14p.

MIRANDA, O.P. et al. Emergency in Brazil of methicillinresistant Staphylococcus aureus isolates carrying SCCmecIV that realated genetically to the USA800 clone. Clinical Microbiology Infection, v.13, n.12, p.1165-72, 2007.

MOREIRA, B.O. Estudo fitoquímico e avaliação da atividade antioxidante dos extratos hexânicos e diclorometânico das folhas de Schinopsis brasiliensis Engl. (Anacardeaceae). 2009. 103p. Dissertação (Mestrado - Área de Concentração em Química) - Instituto de Química, Universidade Federal da Bahia, Salvador.

NIJEVELDT, R. et al. Flavonoids: a review of probable mechanisms of action and potential applications. American Journal of Clinical Nutrition, v.74, n.4, p.418425, 2001.

PESSINI, G.L. et al. Avaliação da atividade antibacteriana e antifúngica de extratos de plantas utilizadas na medicina popular. Revista Brasileira de Farmacognosia, v.13, Supl. 1, p.21-4, 2003.

PRADO, M.C.G.; BARBOSA, D.C.A.;ALVES, J.L.H. Aspecto Morfo-Estruturais da Unidade de Dispersão de Schinopsis brasiliensis Engl. "Baraúna" (Anacardiaceae). Boletim da Sociedade Broteriana de Coimbra, v.67, n.2, p.187-97, 1995.

SARAIVAA.M. Estudo Farmacognóstico e Determinação da Atividade Biológica de Caesalpinia pyramidalis Tull. e Schinopsis brasiliensis Engl. frente a cepas de Staphylococcus aureus MRSA Multirresistentes. 2007. 58 p. Dissertação (Mestrado - Área de Concentração em Farmácia) - Departamento de Ciências Farmacêuticas, Universidade Federal de

Rev. Bras. PI. Med., Campinas, v.15, n.2, p.199-207, 2013. 
Pernambuco, Recife.

SARAIVA, A.M. et al. In vitro evaluation of antioxidant, antimicrobial and toxicity properties of extracts of Schinopsis brasiliensis Engl. (Anacardiaceae). African Journal Pharmacy and Pharmacology. v.5, n.14, p.1724-31, 2011.

STERMITZ, F.R. et al. Synergy in a medicinal plant: antimicrobial action of berberine potentiated by 5'-methoxyhydnocarpin, a multidrug pump inhibitor. Applied Biological Sciences, v.97, n. 4, p.1433-1437, 2000.

SOUZA, M.V.; REIS, C.; PIMENTA, F.C. Revisão sobre a aquisição gradual de resistência de Staphylococcus aureus aos antimicrobianos. Revista de Patologia Tropical, v. 34, n.1, p.27-36, 2005.
SOUZA, O.N. Chemical Constituents of the Leaves of Schinopsis brasiliensis. 1990. 207p. PhD Thesis (Doctor of Philosophy). The Polytechnic of North London, London.

WANG, Z.Y. et al. An approach for the evolution of synergy between antimicrobials. International Journal of Antimicrobial Agents, v.21, n.3, p.274-278, 2003.

WHO (World Heath Organization). The Global Burden of Disease- 2004 UPDATE. WHO Press, 2008. 146p.

ZAIDI-YAHIAOUI, R.; ZAIDI, F.; BESSAI, A.A. Influence of gallic and tannic acids on enzymatic activity and growth of Pectobacterium chrysanthemi (Dickeya chrysanthemi bv. chrysanthemi). African Journal Biotechnology, v.7, n.4, p.482-6, 2008. 